\title{
PENINGKATAN PRODUKTIVITAS KERJA KARYAWAN DEVELOPMENT DI TAMBANG BAWAH TANAH DMLZ (DEEP MILL LEVEL ZONE) PT FREEPORT INDONESIA
}

\author{
INCREASING THE WORK PRODUCTIVITY OF DEVELOPMENT EMPLOYEES IN THE DMLZ \\ UNDERGROUND MINE (DEEP MILL LEVEL ZONE) PT FREEPORT INDONESIA
}

\author{
Norvita irjadani Douw*), M. Syamsul Maarif*), and Lukman M. Baga ${ }^{* *}$ \\ *) Sekolah Bisnis, IPB University \\ Jl. Pajajaran Bogor 16151, Indonesia \\ ${ }^{* * *}$ Departemen Agribisnis, Fakultas Ekonomi dan Manajemen, IPB University \\ Jl. Agatis, IPB Dramaga Campus Bogor 16680, Indonesia
}

\begin{abstract}
The purpose of this research is to analyze the factors that affect the improvement of employee work productivity and formulate managerial implication. Primary data were obtained through the questionnaire of 75 respondents obtained by stratified random sampling. The data are analyzed using descriptive analysis and Structural Equation Model (SEM) with Partial Least Squares (PLS) 3 program. Research has found the factors that impact significantly on worker productivity are salary, work environment and work experience. The managerial implications based on this study are optimize employee salaries structures, repairing communication system at the field, conducting individual work rotation between section, inculuding the development of organizations and promotional systems for employees can increase the productivity of worker Development in the DMLZ (Deep Mill Level Zone) mines PT Freeport Indonesia.
\end{abstract}

Keywords: employee work productivity, SEM-PLS 3, work productivity improvements, underground mine

\begin{abstract}
Abstrak: Tujuan dari penelitian ini adalah untuk menganalisis faktor yang berpengaruh terhadap peningkatan produktivitas kerja karyawan serta memformulasikan implikasi manajerial. Data primer diperoleh melalui kuisioner terhadap 75 responden yang didapat dengan cara pengambilan sampel menggunakan metode stratified random sampling. Analisis data menggunakan analisis deskriptif dan analisis Structural Equation Model (SEM) dengan program Partial Least Squares (PLS) 3. Berdasarkan hasil penelitian ditemukan bahwa faktor yang berpengaruh secara signifikan terhadap produktivitas kerja karyawan adalah gaji, lingkungan kerja dan pengalaman kerja. Implikasi menejerial berdasarkan penelitian ini adalah mengoptimalkan struktur gaji karyawan, memperbaiki sistem komunikasi di lapangan, melakukan rotasi kerja individu antar section, serta pengembangan organisasi dan sistim promosi bagi karyawan dapat meningkatkan produktivitas kerja karyawan Development di tambang bawah tanah DMLZ (Deep Mill Level Zone) PT Freeport Indonesia.
\end{abstract}

Kata kunci: peningkatan produktivitas kerja, produktivitas kerja karyawan, SEM-PLS 3, tambang bawah tanah

\footnotetext{
${ }^{1}$ Corresponding author:

Email:ndouw@fmi.com
} 


\section{PENDAHULUAN}

Dalam suatu organisasi atau perusahaan memerlukan produktivitas untuk mencapai tujuan yang telah ditetapkan. Produktivitas merupakan aspek penting pada sebuah perusahaan dalam menentukan keberlangsungan usaha dimasa depan. Produktivitas merupakan penggunaan sumber daya (input) secara efektif dan efisien untuk menghasilkan atau meningkatkan hasil (output) barang dan jasa. Dalam upaya untuk meningkatkan produktivitas kerja karyawan, setiap perusahaan harus memperhatikan faktor-faktor yang mempengaruhi produktivitas kerja (Wirawan et al. 2018). Karyawan dikatakan produktif jika mampu menghasilkan barang dan jasa sesuai dengan target yang ditentukan dalam jangka waktu yang singkat dan tepat. Produktivitas meningkat maka efisiensi (waktu, bahan, tenaga), sistem kerja, teknik produksi, dan keterampilan tenaga kerja juga akan meningkat (Mukti dan Asmaroni, 2020). Produktivitas kerja dimaknai sebagai sebuah kondisi untuk mengukur tingkat kemampuan dalam menghasilkan produk, baik diukur secara individual, kelompok maupun organisasi (Rismayanti et al. 2020). Produktivitas kerja karyawan dipengaruhi oleh beberapa faktor yaitu faktor internal yang berhubungan dengan karyawan itu sendiri seperti pendidikan, keterampilan, disiplin, sikap, motivasi, gizi dan kesehatan ataupun faktor eksternal yang berhubungan dengan lingkungan perusahaan, kebijakan perusahaan dan kebijakan pemerintah secara keseluruhan, upah, sarana produksi, iklim dan lingkungan kerja (Simanjuntak, 1998).

PT Freeport Indonesia merupakan salah satu perusahaan tambang mineral terkemuka didunia, yang merupakan afiliasi dari Freeport-McMoRan (FCX) dan Mining Industry Indonesia (MIND ID). PT Freeport Indonesia melakukan proses penambangan dan pengolahan bijih menghasilkan konsentrat yang mengandung tembaga, emas dan perak. Dalam melaksanakan kegiatan penambangan, PT Freeport Indonesia menggunakan sistem tambang terbuka dan tambang bawah tanah. Tambang terbuka Grasberg saat ini memasuki tahap penurunan produksi sejak tahun 2011, kemudian seiring dengan berkurangnya jumlah pushback yang aktif, maka tambang bawah tanah akan menjadi sistem penambangan utama. Tambang bawah tanah DMLZ (Deep Mill Level Zone) merupakan salah satu tambang bawah tanah yang menggunakan sistem Block Caving dengan rencana target produksi di akhir tahun 2020 sebesar 40.000 ton bijih per hari dan peningkatan produksi menjadi 80.000 ton per hari di tahun 2022. Untuk mencapai target produksi tersebut diperlukan keterlibatan semua pihak yang akan mendukung persiapan peningkatan produksi, salah satunya adalah kegiatan Pre-Production seperti pekerjaan Development, ground support dan Caving. Development merupakan pekerjaan pengembangan tambang, dilakukan dengan pembuatan terowongan baik berupa terowongan untuk keperluan produksi maupun terowongan untuk sarana-sarana pendukung produksi seperti crusher, loading point, grizzly, terminal, perbengkelan dan perkantoran. Tim Development Engineering akan membuat penjadwalan kemajuan tambang dan mengirimkan target bulanan serta tahunan yang harus dicapai. Penjadwalan dilakukan untuk menentukan area prioritas yang harus dikerjakan berdasarkan waktu, melakukan evaluasi pekerjaan, mencarikan solusi terhadap permasalahan yang terjadi. Permasalahan yang terjadi di tambang bawah tanah DMLZ (Deep Mill Level Zone) adalah menurunnya tingkat produktivitas kerja karyawan Development. Dimana berdasarkan data tahun 2018 menunjukkan terjadinya penurunan pencapaian pekerjaan sebesar $50 \%$ yang mengakibatkan tidak tercapainya target bulanan maupun target tahunan yang telah ditetapkan dan kondisi ini terus berlanjut hingga tahun 2020 (Gambar 1 dan 2). Hal ini perlu dikaji dan dilakukan analisis terhadap faktor yang berpengaruh terhadap peningkatan produktivitas kerja karyawan sehingga dapat memformulasikan implementasi manajerial untuk meningkatkan produktivitas kerja karyawan. Karena dengan tingginya produktivitas kerja, dapat menghemat waktu dan biaya yang dikeluarkan perusahaan untuk meningkatkan produksi. Produktivitas karyawan yang tinggi akan membawa kemajuan bagi perusahaan dalam mencapai hasil yang maksimal dan berkualitas (Saputra et al. 2020).

Produktivitas kerja karyawan dipengaruhi oleh beberapa faktor yaitu faktor internal yang berhubungan dengan karyawan itu sendiri seperti pendidikan, keterampilan, disiplin, sikap, motivasi, gizi dan kesehatan ataupun faktor eksternal yang berhubungan dengan lingkungan perusahaan, kebijakan perusahaan dan kebijakan pemerintah secara keseluruhan, upah, sarana produksi, iklim dan lingkungan kerja (Simanjuntak, 1998). Menurut Ravino (1985) menyatakan bahwa produktivitas kerja dipengaruhi oleh faktor pendidikan, keterampilan, disiplin, sikap, etika kerja, motivasi gaji, kesehatan, teknologi, manajemen dan kesempatan berprestasi. Penelitian Prasetyo (2016) faktor yang 
mempengaruhi produktivitas tenaga kerja adalah pendidikan, keterampilan, disiplin, motivasi, jaminan sosial, sarana produksi, sikap dan etika kerja, tingkat penghasilan, lingkungan dan iklim kerja, teknologi dan kesempatan berprestasi. Sehingga berdasarkan teori para ahli dan penelitian terdahulu, maka faktor yang diteliti dalam penelitian adalah pengaruh pendidikan dan pelatihan, motivasi, kedisiplinan, keterampilan, pengalaman kerja, gaji atau upah dan lingkungan kerja terhadap peningkatan produktivitas kerja karyawan Development di tambang bawah tanah DMLZ (Deep Mill Level Zone), PT Freeport Indonesia.

Pendidikan dan pelatihan dalam suatu organisasi atau perusahaan merupakan suatu upaya untuk meningkatkan mutu sumber daya manusia, hal ini harus dilakukan terus menerus dan ditingkatkan sesuai dengan kemajuan dan perkembangan organisasi atau perusahaan (Sedarmayanti, 2009). Tingkat pendidikan berpengaruh terhadap keterampilan tenaga kerja dan karakteristik individu sehingga dapat memberikan wawasan yang lebih luas untuk berinisiatif dan berinovasi dalam meningkatkan keterampilan kerjanya dan karakteristiknya (Latifah, 2020). Pelatihan dan pengembangan juga memiliki peran penting untuk mencapai kesuksesan dan pertumbuhan perusahaan (Rachmawati, 2020).

Motivasi merupakan suatu keadaan atau kondisi yang mendorong, merangsang, menggerakan seseorang untuk melakukan suatu kegiatan agar dapat mencapai tujuannya (Marayasa dan Faradila, 2019). Manfaat motivasi yang terpenting adalah menciptakan gairah kerja, sehingga meningkatkan produktivitas kerja. Motivasi berhubungan erat dengan produktivitas kerja, karena semakin tinggi tingkat motivasi seseorang, dia akan bersemangat untuk menyelesaikan pekerjaan menjadi lebih cepat dan berkualitas sesuai dengan standar yang ditetapkan (Liana, 2020).

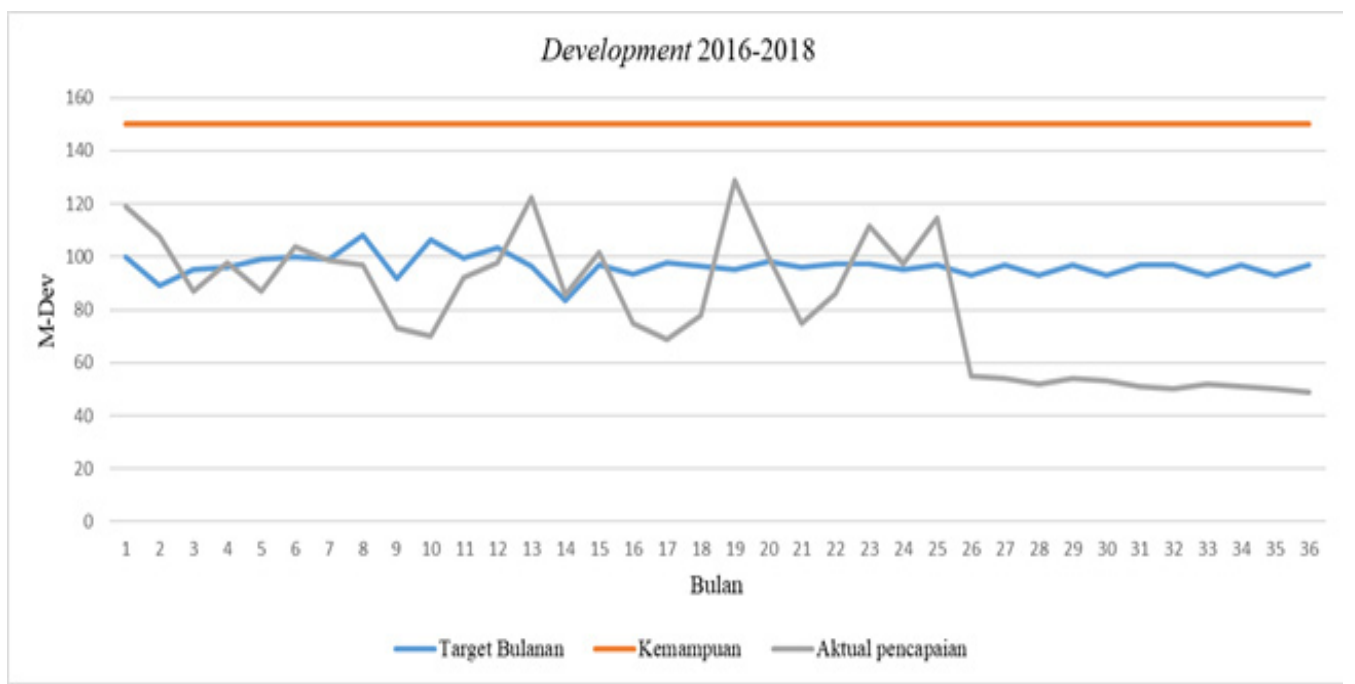

Gambar 1. Data Pencapaian Pekerjaan Development 2016-2018

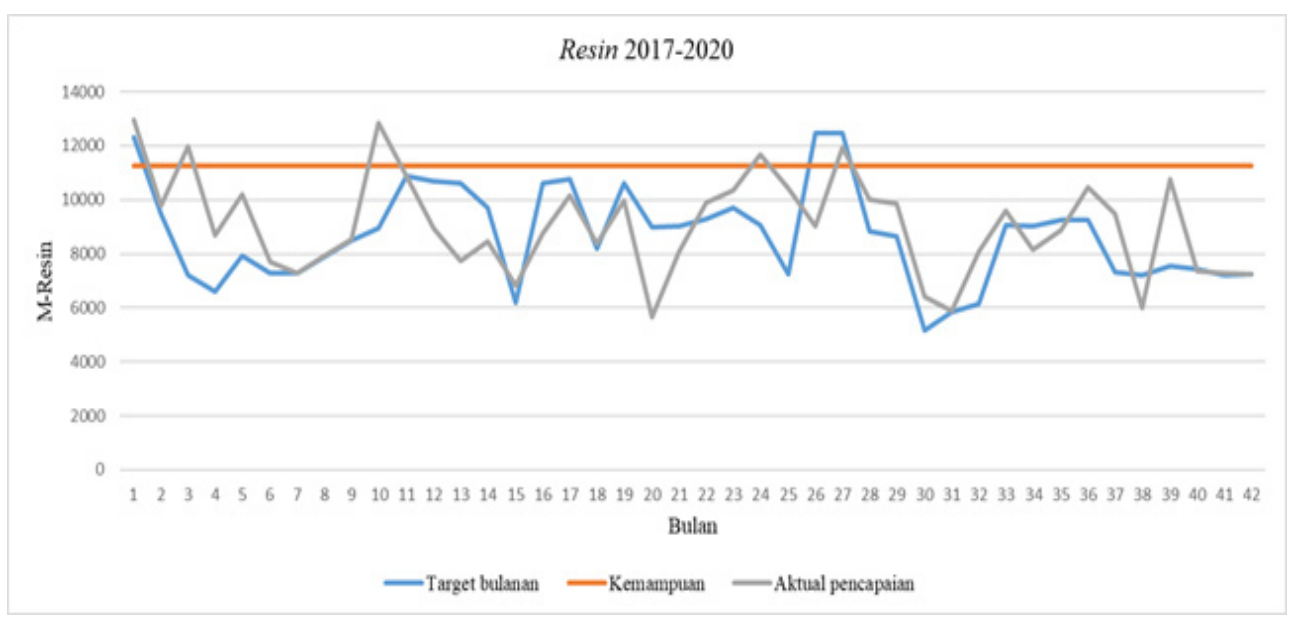

Gambar 2. Data Pencapaian Pekerjaan Development 2017-2020 
Kedisiplinan merupakan kesadaran dan kesediaan sesorang dalam menaati semua peraturan serta normanorma sosial yang berlaku di dalam organisasi atau perusahaan (Hasibuan, 2012). Menurut Ma'arif dan Kartika (2012) tujuan dan manfaat ditegakkanya kedisiplinan kerja adalah untuk memastikan perilaku karyawan sesuai dengan peraturan yang telah ditetapkan oleh organisasi atau perusahaan, membantu karyawan untuk mempunyai kinerja tinggi, produktif dalam bekerja, menciptakan serta mempertahankan rasa hormat dan saling percaya antara pimpinan dan bawahanya, Skill atau keterampilan adalah kecakapan spesifik dari karyawan untuk menyelesaikan suatu pekerjaan secara cepat dan tepat. Produktivitas kerja dapat dicapai apabila tenaga kerja mempunyai skill atau keterampilan kerja yang dapat diterapkan dalam melakukan pekerjaannya sehari-hari di organisasi atau perusahaan (Latifah, 2020). Peningkatan skill atau keterampilan kerja karyawan dapat dilakukan melalui training-training serta pelatihan kerja.

Lingkungan kerja yang baik serta menyenangkan dapat meningkatkan gairah dan semangat kerja pegawai dalam suatu organisasi serta akan menimbulkan suatu emosi yang baik dalam menyelesaikan tugas yang menjadi tanggung jawabnya (Junianti et al. 2020). Lingkungan kerja merupakan berbagai situasi dan kondisi yang terdapat disekitar tempat kerja baik yang menyangkut aspek fisik dan non fisik, maupun yang berhubungan dengan aspek psikologis (Lazuardi, 2020).

Gaji merupakan kompensasi langsung yang diberikan oleh perusahaan kepada karyawan dalam bentuk uang berdasarkan waktu tertentu. Fungsi gaji adalah untuk menarik pekerja yang memiliki kemampuan ke dalam organisasi, memotivasi pekerja untuk menunjukan prestasi yang tinggi dan menjaga prestasi pekerja dalam periode yang panjang (Komaruddin, 2013). Upah merupakan segala sesuatu yang diterima oleh pekerja sebagai tanda balas jasa atas suatu pekerjaan terhadap perusahaan (Mukti dan Asmaroni, 2020).

Pengalaman kerja merupakan sebuah proses pembentukan keterampilan atau pengetahuan tentang metode pekerjaan karena keterlibatan karyawan tersebut dalam melaksanakan tugas pekerjaannya (Manulang, 2005). Pengalaman kerja berpengaruh terhadap produktivitas karyawan karena pengalaman kerja dapat menunjang terciptanya produktivitas yang optimal (Nangoy et al. 2020).

\section{METODE PENELITIAN}

Penelitian ini menggunakan analisa kualitatif dan kuantitatif, pendekatan kuantitatif dilakukan dengan metode survey kuisioner sebagai instrumen pengumpulan data. Sedangkan pendekatan kualitatif dilakukan dengan mengumpulkan literatur dan data pendukung lainnya. Lokasi penelitian ini dilakukan di tambang bawah tanah DMLZ (Deep Mill Level Zone), PT Freeport Indonesia. Waktu penelitian dilakukan pada bulan Agustus hingga Oktober 2020. Penarikan contoh dilakukan dengan menggunakan metode Stratified random sampling. Populasi pada penelitian ini adalah seluruh karyawan Development di tambang bawah tanah DMLZ PT Freeport Indonesia yang berjumlah 95 karyawan. Contoh yang berhasil di ambil adalah 75 karyawan atau $78 \%$ dari populasi karyawan.

Data yang terkumpul diolah melalui proses editing, coding, scoring, entry, cleaning, analyzing, dan interpretasi data. Pengolahan data menggunakan perangkat lunak microsoft Excel dan analisis data dilakukan dengan menggunakan analisis Structural Equation Model (SEM) dengan program Partial Least Squares (PLS) 3. Evaluasi model PLS dilakukan dengan melakukan evaluasi terhadap model pengukuran (outer model) dan model struktural (inner model) yang dilakukan secara bersamaan (Jogiyanto, 2011). Variabel laten merupakan variabel yang tidak dapat diobservasi secara langsung, sehingga untuk dapat mengobservasi variabel laten dibutuhkan variabel manifest atau indikator yang dapat diobservasi secara langsung (Sarwono dan Narimawati, 2015). Tabel 1 menggambarkan tujuh variabel laten yang digunakan pada penelitian ini dan Gambar 3 menunjukan model jalur hubungan antar variabel laten dan variabel manifest.

Penelitian ini dilakukan untuk menganalisis permasalahan yang terjadi di tambang bawah tanah DMLZ yaitu menurunnya produktivitas kerja karyawan Development. Analisis dilakukan dengan menggunakan Structural Equation Modeling (SEM) dengan program Partial Least Squares (PLS) 3. Hasil analisis ini menunjukkan faktor yang berpengaruh terhadap peningkatan produktivitas kerja karyawan sehingga dapat menformulasikan implikasi manajerial untuk meningkatkan produktivitas kerja karyawan Development di tambang bawah tanah DMLZ PT Freeport Indonesia. Kerangka pemikiran selengkapnya pada Gambar 4. 


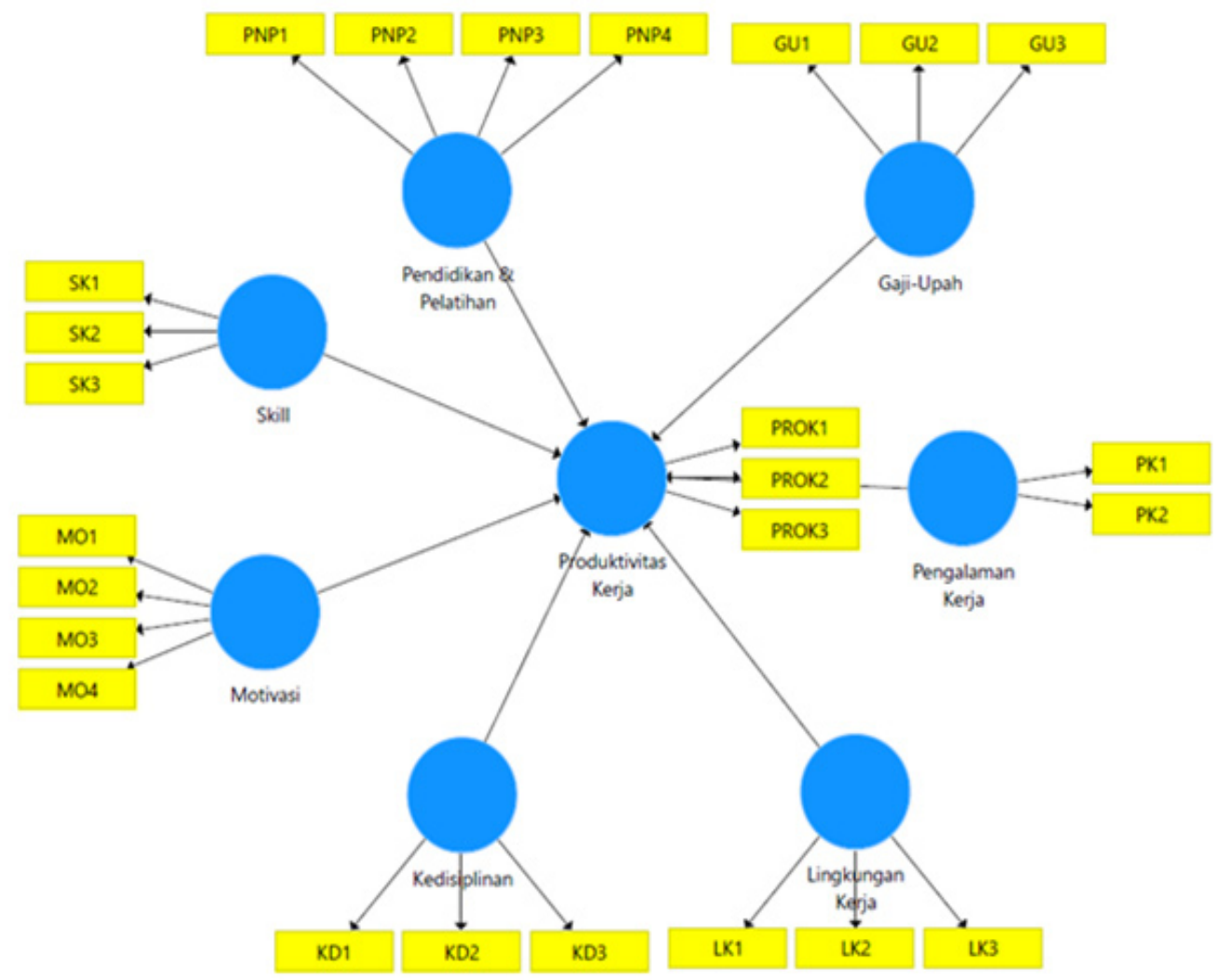

Gambar 3. Model jalur hubungan antar variabel laten dan variabel manifest

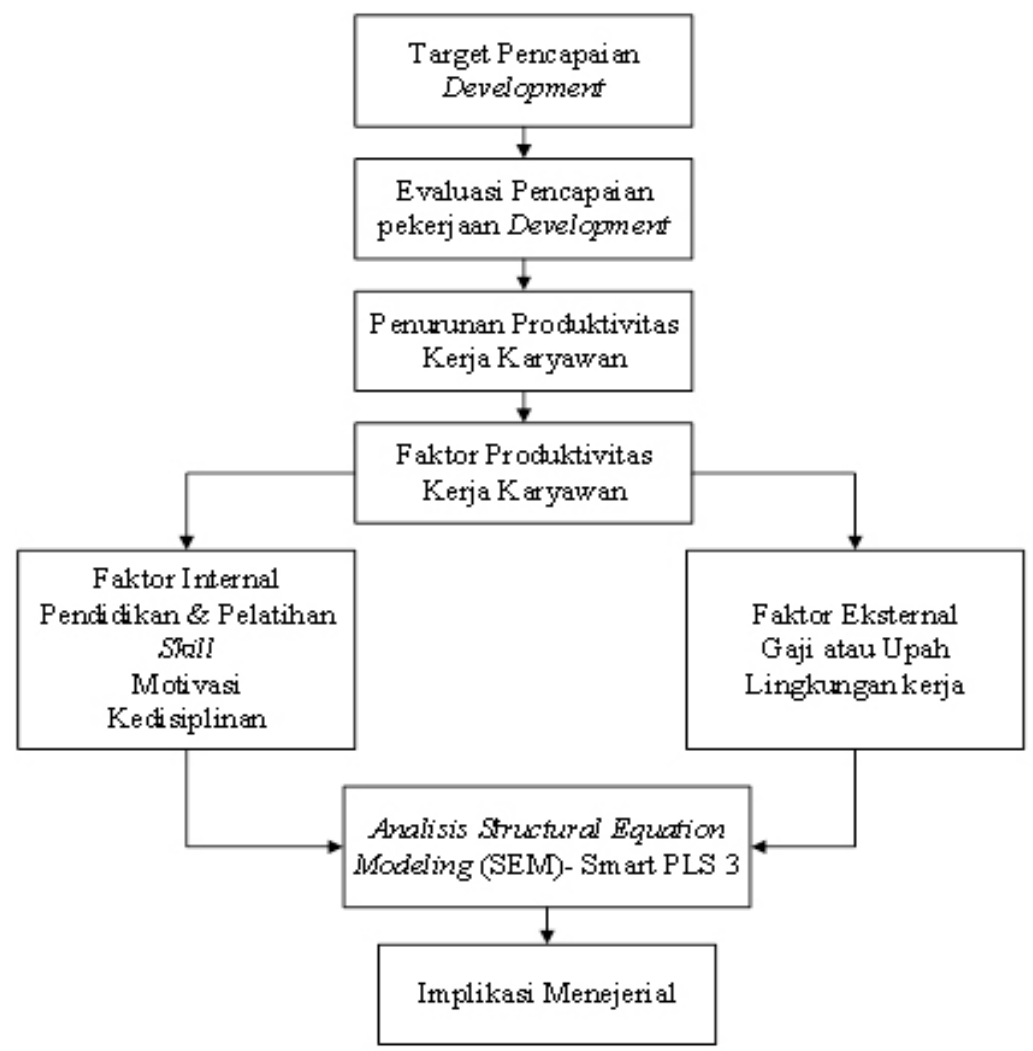

Gambar 4. Kerangka pemikiran penelitian 
Tabel 1. Variabel laten dan manifest

\begin{tabular}{|c|c|}
\hline Variabel laten & Variabel manifest \\
\hline \multirow[t]{4}{*}{ Pendidikan \& pelatihan (PNP) } & Tingkat Ketrampilan yang sesuai (PNP1) \\
\hline & Tingkat Pengetahuan yang sesuai dengan pekerjaan (PNP2) \\
\hline & Peningkatan kompetensi (PNP3) \\
\hline & Pengembangan \& Rotasi Kerja (PNP4) \\
\hline \multirow[t]{3}{*}{ Skill atau ketrampilan (SK) } & Ketrampilan terhadap pekerjaan (SK1) \\
\hline & Kualitas \& Kuantitas hasil kerja (SK2) \\
\hline & Penguasaan terhadap peralatan kerja (SK3) \\
\hline \multirow[t]{4}{*}{ Motivasi (MO) } & Kepuasan (MO1) \\
\hline & Keselamatan kerja (MO2) \\
\hline & Hubungan Sosial antar Karyawan (MO3) \\
\hline & Aktualisasi Diri (MO4) \\
\hline \multirow[t]{3}{*}{ Kedisiplinan (KD) } & Ketepatan waktu (KD1) \\
\hline & Ketaatan terhadap peraturan (KD2) \\
\hline & Tanggung Jawab kerja (KD3) \\
\hline \multirow[t]{3}{*}{ Lingkungan kerja (LK) } & Lingkungan Fisik (LK1) \\
\hline & Hubungan atasan dan bawahan (LK2) \\
\hline & Hubungan sesama rekan kerja (LK3) \\
\hline \multirow[t]{3}{*}{ Gaji atau upah (GU) } & Pembayaran Gaji tepat waktu (GU1) \\
\hline & Kepuasan terhadap gaji (GU2) \\
\hline & Tunjangan Perusahaan (GU3) \\
\hline \multirow[t]{2}{*}{ Pengalaman Kerja (PK) } & Masa kerja (PK1) \\
\hline & Penguasaan terhadap pekerjaan dan peralatan (PK2) \\
\hline \multirow[t]{3}{*}{ Produktivitas Kerja (PROK) } & Efektivitas (PROK1) \\
\hline & Efisiensi waktu (PROK2) \\
\hline & Penguasaan terhadap pekerjaan (PROK3) \\
\hline
\end{tabular}

Hipotesis dilakukan untuk mengetahui faktor yang berpengaruh terhadap peningkatan produktivitas kerja karyawan Development di tambang bawah tanah DMLZ (Deep Mill Level Zone) PT Freeport Indonesia. Pengujan hipotesis dapat dilihat dari hasil analisis bootstrapping yaitu dengan melihat nilai path coeficient dan nilai t hitung (Irawan et al. 2015). Nilai path coefficient menunjukkan tingkat signifikansi dalam pengujian hipotesis, ditunjukkan oleh nilai t hitung harus di atas nilai t tabel dengan taraf kepercayaan 95\% atau tingkat signifikansi alpha 5\% yaitu sebesar 1.668. Jika nilai $\mathrm{t}$ hitung $>\mathrm{t}$ tabel (1.668) maka perumusan hipotesis diterima, namun jika nilai $\mathrm{t}$ hitung $<\mathrm{t}$ tabel (1.668) maka perumusan hipotesis ditolak. Berikut adalah hipotesis yang diuji pada penelitian ini:

H1: Gaji berpengaruh terhadap peningkatan produktivitas kerja karyawan

H2: Kedisiplinan berpengaruh terhadap peningkatan produktivitas kerja karyawan

H3: Lingkungan kerja berpengaruh terhadap peningkatan produktivitas kerja karyawan
H4: Motivasi berpengaruh terhadap peningkatan produktivitas kerja karyawan

H5: Pendidikan dan pelatihan berpengaruh terhadap peningkatan produktivitas kerja karyawan

H6: Pengalaman kerja berpengaruh terhadap peningkatan produktivitas kerja karyawan

H7: Skill berpengaruh terhadap peningkatan produktivitas kerja karyawan

\section{HASIL}

\section{Karasteristik Responden}

Responden dalam penelitian ini adalah karyawan Development di tambang bawah tanah DMLZ (Deep Mill Level Zone), PT Freeport Indonesia yang berjumlah 75 karyawan. Karakteristik responden yang diteliti yaitu berdasarkan jenis kelamin, usia, tingkat pendidikan dan masa kerja, dapat dilihat pada Tabel 2. Berdasarkan jenis kelamin, mayoritas responden karyawan Development 
di tambang bawah tanah DMLZ (Deep Mill Level Zone) PT Freeport Indonesia adalah karyawan laki-laki yaitu dengan presentase sebesar 98,67\% (74 orang dan 1,33\% atau 1 orang karyawan berjenis kelamin perempuan. Usia responden terbanyak berada pada rentan usia $31-40$ tahun dengan presentase $53,33 \%$ berjumlah 40 orang yang merupakan usia produktif untuk bekerja. Berdasarkan latar belakang pendidikan bahwa mayoritas karyawan memiliki latar belakang pendidikan Sekolah Menengah Umum (SMU) yaitu sebanyak 45 orang dengan presentase $60 \%$, Sarjana berjumlah 26 orang dengan presentase $34,67 \%$ dan posisi yang paling sedikit adalah lulusan Sekolah Dasar dan Magister masing-masing berjumlah 2 Orang dengan presentase 2,67\%. Masa kerja karyawan tertinggi adalah 6-10 tahun sebanyak 34 orang $(45,33 \%)$ merupakan masa produktif karyawan untuk bekerja, masa kerja terendah $>15$ tahun berjumlah 14 orang dengan persentase $18,67 \%$. Sehingga dapat disimpulkan bahwa karyawan yang memiliki pengalaman diatas 5 tahun berjumlah $80 \%$ dari total karyawan atau sebanyak 60 orang.

\section{Analisis Model Structural Equation Modeling - Partial Least Square (PLS)}

\section{Evaluasi Outer Model}

Evaluasi outer model bertujuan untuk menilai validitas dan reliabilitas model. Analisis outer model mengambarkan hubungan antar variabel laten dengan indikator-indikatornya, dan dapat mendefinisikan bagaimana setiap indikator berhubungan dengan variabel latennya (Rachmawati, 2020).

\section{Convergent Validity}

Nilai convergent validity merupakan nilai loading factor pada variabel laten dengan indikatornya. Menurut (Ghozali, 2014) pada penelitian tahap awal dari pengembangan skala pengukuran nilai loading factor 0,5-0.,6 sudah dianggap valid. Menurut (Asbari et al. 2020), indikator dikatakan valid apabila nilai loading factor $>=0,5$. Pada penelitian ini nilai loading factor yang digunakan adalah 0,5 . Hasil pengujian tahap awal dengan PLS alogaritm, terdapat empat indikator variabel yang memiliki nilai factor loading kurang dari 0,5 , yaitu MO1 $(0,356), \operatorname{KD} 2(0,457), \operatorname{LK} 1(0,360)$, dan GU3 $(0,372)$, sehingga harus dihilangkan dan dilakukan pengujian ulang. Pada Gambar 5 menunjukan output
PLS alogaritm setelah dilakukan pengujian ulang, dimana seluruh indikator dari variabel telah memiliki nilai factor loading diatas 0,5 sehingga model telah memenuhi kriteria convergent validity.

\section{Discriminant Validity}

Discriminant validity merupakan nilai dari cross loading factor yang berfungsi untuk mengetahui apakah konstruk memiliki diskriminan yang memadai, berdasarkan hasil pengujian pada Tabel 3 menunjukan bahwa perbandingan nilai loading pada konstruk yang dituju telah memiliki nilai yang lebih besar jika dibandingkan dengan nilai loading pada konstruk lainnya sehingga model telah memenuhi discriminant validity (Ghozali, 2014).

\section{Average Variance Extracted (AVE)}

Pengujian tingkat kevalidan suatu pengukuran dapat dilihat dari nilai AVE (Average Variables Extracted). Nilai AVE yang dihasilkan dari hasil ulangan kedua PLS Algorithm menunjukkan bahwa tidak terdapat konstruk atau variabel laten yang berada dibawah 0,5 . Hasil tersebut dapat dilihat pada Tabel 4.

Tabel 2 Karasteristik Responden

\begin{tabular}{llcc}
\hline \multicolumn{2}{c}{ Karasteristik } & Jumlah (n) & $\begin{array}{c}\text { Persentase } \\
(\%)\end{array}$ \\
\hline Jenis Kelamin & Laki-laki & 74 & 98,67 \\
& Perempuan & 1 & 1,33 \\
Usia (Tahun) & $20-30$ & 14 & 18,67 \\
& $31-40$ & 40 & 53,33 \\
& $41-50$ & 16 & 21,33 \\
& 51-60 & 5 & 6,67 \\
Pendidikan & SD & 2 & 2,67 \\
& SMP & 0 & 0,00 \\
& SMU & 45 & 60,00 \\
& D1 & 0 & 0,00 \\
& D3 & 0 & 0,00 \\
& S1 & 26 & 34,67 \\
Masa Kerja & S2 & 2 & 2,67 \\
(Tahun) & 1 s/d 5 & 15 & 20,00 \\
& 6 s/d 10 & 34 & 45,33 \\
& 11 s/d 15 & 12 & 16,00 \\
& $>15$ & 14 & 18,67 \\
\hline
\end{tabular}




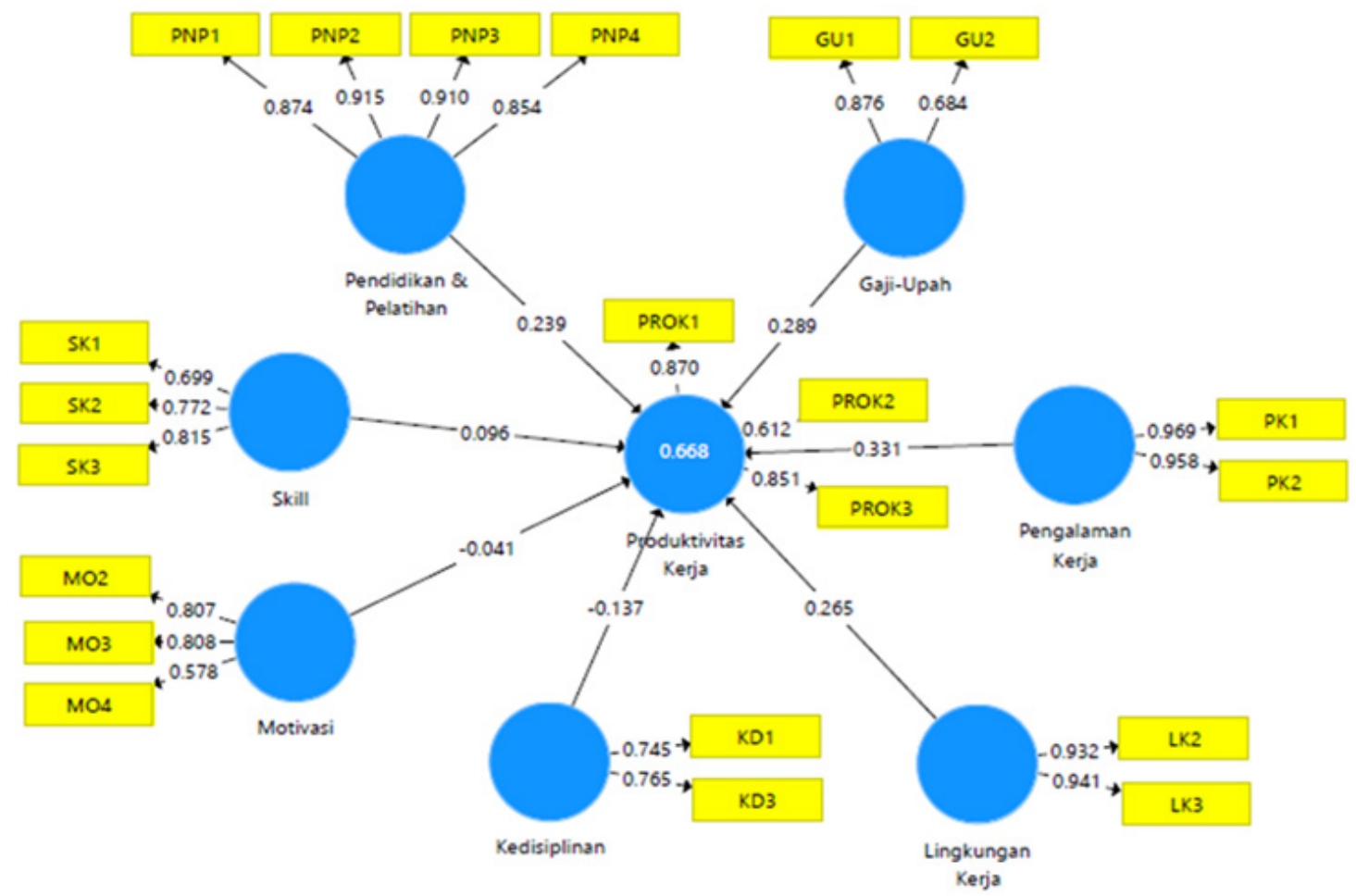

Gambar 5. Output PLS algorithm kedua

Tabel 3. Discriminant validity pada setiap variabel laten

\begin{tabular}{lcccccccc}
\hline Variabel & GU & KD & LK & MO & PNP & PK & SK & PROK \\
\hline GU & 0,786 & & & & & & & \\
KD & 0,241 & 0,755 & & & & & & \\
LK & 0,462 & 0,387 & 0,937 & & & & & \\
MO & 0,503 & 0,492 & 0,698 & 0,739 & & & & \\
PNP & 0,214 & 0,592 & 0,453 & 0,381 & 0,889 & & & \\
PK & 0,325 & 0,577 & 0,381 & 0,365 & 0,768 & 0,964 & & \\
SK & 0,226 & 0,569 & 0,392 & 0,500 & 0,689 & 0,642 & 0,763 & \\
PROK & 0,539 & 0,402 & 0,589 & 0,483 & 0,644 & 0,677 & 0,544 & 0,787 \\
\hline
\end{tabular}

Tabel 4. Nilai AVE dan Communality PLS Algorithm

\begin{tabular}{lc}
\hline Variabel & Average Variance Extracted (AVE) \\
\hline Gaji /Upah (GU) & 0,617 \\
Kedisiplinan (KD) & 0,570 \\
Lingkungan Kerja (LK) & 0,877 \\
Motivasi (MO) & 0,546 \\
Pendidikan \& Pelatihan (PNP) & 0,790 \\
Pengalaman Kerja (PK) & 0,929 \\
Skill (SK) & 0,583 \\
Produktivitas Kerja (PROK) & 0,619 \\
\hline
\end{tabular}


Uji Reliabilitas dilakukan dengan melihat nilai composite reliability dan cronbach's alpha. Pada Tabel 5 terlihat bahwa nilai reliabilitas ketujuh variabel laten diatas 0,7 dari sudut nilai composite reliability, pada nilai cronbach's alfa menunjukan bahwa hampir semua variabel laten dapat dikatakan handal. Hal ini terlihat bahwa variabel laten lingkungan kerja, motivasi, pendidikan dan pelatihan, pengalaman kerja, skill dan produktivitas yang memiliki cronbach's alpha yang nilainya lebih besar dari 0,6 , sedangkan variabel laten kedisiplinan dan gaji atau upah yang memiliki nilai pada rentang 0,0-0,4 yang berarti kurang andal. Sehingga dapat disimpulkan bahwa keenam variabel memiliki tingkat kekonsistenan yang baik dan keakuratan yang cukup andal dalam mengukur seluruh konstruk atau telah memenuhi syarat reliable.

\section{Analisis Inner Model (Model Struktural)}

Analisis inner model atau model struktural yang bertujuan untuk menganalisis tingkat estimasi antar variabel bebas terhadap variabel terikat yaitu produktivitas kerja. Berdasarkan pengolahan data, besarnya koefisien determinasi (R Square) sebesar 0,668 atau $66,8 \%$, variabel endogen yang diperoleh dari model struktural menunjukkan bahwa nilainya berada pada level model kuat (Heir et al. 2014). Sisanya sebesar $33,2 \%$ dipengaruhi oleh variabel lain yang tidak diteliti dalam penelitian ini. Path Coeficient merupakan nilai koefisien jalur atau besarnya hubungan atau pengaruh konstruk laten, dilakukan dengan analisis bootsrapping. Analisis bootstrapping bertujuan untuk menguji hipotesis dengan melihat nilai path coefficient yang menunjukkan signifikasi. Hasil analisis dengan proses bootstrapping pada Gambar 6 menunjukan semua variabel berpengaruh signifikan terhadap peningkatan produktivitas kerja.

Analisis Pengaruh Indikator Gaji atau upah, Kedisiplinan, Lingkungan kerja, Motivasi, Pendidikan \& pelatihan, Pengalaman kerja dan Skill terhadap Peningkatan produktivitas kerja karyawan.

Hipotesis dapat dilihat dari hasil analisis bootstrapping yaitu dengan melihat nilai path coeficient dan nilai $\mathrm{t}$ hitung (Irawan et al. 2015). Nilai path coefficient menunjukkan tingkat signifikansi dalam pengujian hipotesis, ditunjukkan oleh nilai thitung harus di atas nilai t tabel dengan tingkat signifikansi alpha 5\%, yaitu sebesar 1,668 . Jika nilai t hitung $>t$ tabel $(1,668)$ maka perumusan hipotesis diterima, namun jika nilai t hitung $<\mathrm{t}$ tabel $(1,668)$ maka perumusan hipotesis ditolak. Secara ringkas hasil output analisis bootstrapping yang menunjukkan hasil path coefficient disajikan pada Tabel 6. Berdasarkan hasil analisis bootstrapping dapat disimpulkan bahwa:

1. H1: Variabel gaji atau upah berpengaruh terhadap produktivitas kerja karyawan. Hal ini dibuktikan dengan nilai $t$ hitung yang lebih besar dari nilai $t$ tabel, pada taraf nyata $5 \%(3,148>1,668)$ sehingga H1 diterima.

2. H2: kedisiplinan tidak berpengaruh terhadap produktivitas kerja karyawan. Hal ini dibuktikan dengan nilai t hitung yang lebih kecil dari nilai $t$ tabel, pada taraf nyata $5 \%(1,328<1,668)$ sehingga $\mathrm{H} 2$ ditolak.

Tabel 5. Nilai Composite Reliability dan Cronbach's Alpha

\begin{tabular}{lcc}
\hline Variabel & Composite Reliability & Cronbach's Alpha \\
\hline Gaji -Upah (GU) & 0,761 & 0,396 \\
Kedisiplinan (KD) & 0,726 & 0,245 \\
Lingkungan Kerja (LK) & 0,935 & 0,860 \\
Motivasi (MO) & 0,779 & 0,629 \\
Pendidikan \& Pelatihan (PNP) & 0,938 & 0,911 \\
Pengalaman Kerja (PK) & 0,963 & 0,924 \\
Skill (SK) & 0,807 & 0,669 \\
Produktivitas Kerja (PROK) & 0,826 & 0,687 \\
\hline
\end{tabular}


3. H3: Variabel lingkungan kerja berpengaruh terhadap produktivitas kerja karyawan. Hal ini dibuktikan dengan nilai $\mathrm{t}$ hitung yang lebih besar dari nilai $\mathrm{t}$ tabel, pada taraf nyata $5 \%(1,948>1,668)$ sehingga $\mathrm{H} 3$ diterima.

4. H4: Variabel motivasi tidak berpengaruh terhadap produktivitas kerja karyawan. Hal ini dibuktikan dengan nilai $t$ hitung yang lebih kecil dari nilai $t$ tabel, pada taraf nyata $5 \%(3,148<1,668)$ sehingga H4 ditolak.

5. H5: Variabel pendidikan dan pelatihan tidak berpengaruh terhadap produktivitas kerja karyawan. Hal ini dibuktikan dengan nilai $t$ hitung yang lebih kecil dari nilai t tabel, pada taraf nyata 5\% $(1,435<1,668)$ sehingga H5 ditolak.
6. H6: Variabel Pengalaman kerja berpengaruh terhadap produktivitas kerja karyawan. Hal ini dibuktikan dengan nilai t hitung yang lebih besar dari nilai $t$ tabel, pada taraf nyata $5 \%(1,948>1,668)$ sehingga H6 diterima.

7. H7: Variabel skill atau keterampilan tidak berpengaruh terhadap produktivitas kerja karyawan. Hal ini dibuktikan dengan nilai $t$ hitung yang lebih kecil dari nilai $\mathrm{t}$ tabel, pada taraf nyata $5 \%$ $(0,791<1,668)$ sehingga $\mathrm{H} 7$ ditolak.

Berdasarkan tabel hasil uji hipotesis disimpulkan bahwa variabel yang berpengaruh positif dan signifikan terhadap peningkatan produktivitas kerja karyawan adalah: gaji, lingkungan kerja dan pengalaman kerja.

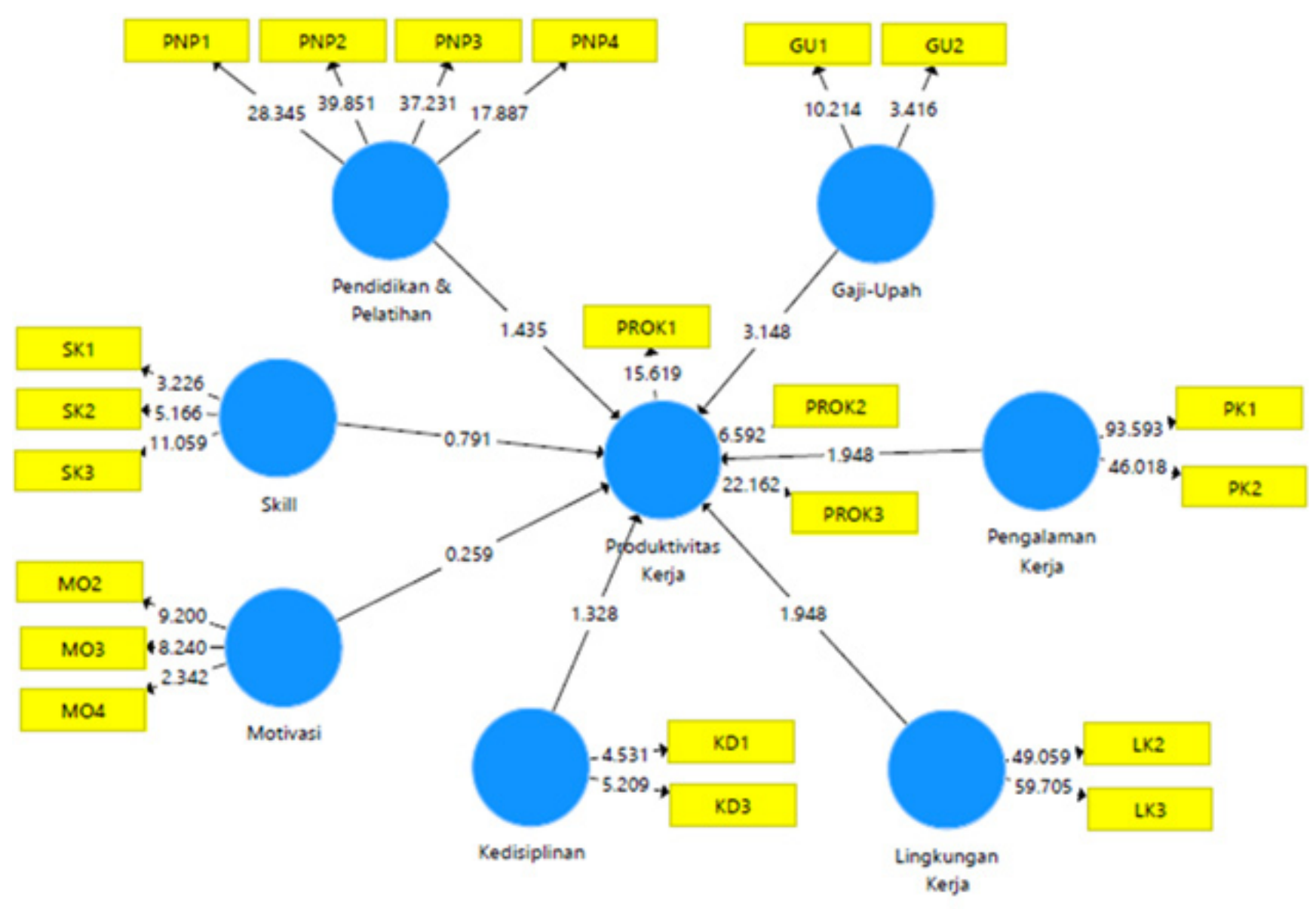

Gambar 6. Output bootstapping 
Tabel 6. Hasil analisis bootstrapping Gaji atau upah, kedisiplinan, lingkungan kerja, motivasi, pendidikan dan pelatihan, pengalaman kerja dan skill terhadap produktivitas kerja karyawan

\begin{tabular}{llccc}
\hline Hipotesa & Variabel & Original Sample $(\mathrm{O})$ & T Statistics & P Values \\
\hline H1 & Gaji atau upah $\rightarrow$ Produktivitas kerja & 0,289 & 3,148 & 0,002 \\
H2 & Kedisiplinan $\rightarrow$ Produktivitas kerja & $-0,137$ & 1,328 & 0,185 \\
H3 & Lingkungan Kerja $\rightarrow$ Produktivitas kerja & 0,265 & 1,948 & 0,052 \\
H4 & Motivasi $\rightarrow$ Produktivitas kerja & 0,041 & 0,259 & 0,796 \\
H5 & Pendidikan \& Pelatihan $\rightarrow$ Produktivitas kerja & 0,239 & 1,435 & 0,152 \\
H6 & Pengalaman Kerja $\rightarrow$ Produktivitas kerja & 0,331 & 1,948 & 0,052 \\
H7 & Skill $\rightarrow$ Produktivitas kerja & $-0,096$ & 0,791 & 0,430 \\
\hline
\end{tabular}

\section{H1: Gaji atau upah berpengaruh terhadap produktivitas kerja karyawan}

Berdasarkan Tabel 6 diketahui bahwa variabel gaji memiliki hubungan positif tertinggi dan berpengaruh secara signifikan terhadap produktivitas kerja karyawan. Hal ini dibuktikan dengan nilai t hitung yang lebih besar dari nilai $\mathrm{t}$ tabel, pada taraf nyata $5 \%(3,148>1,668)$ sehingga $\mathrm{H} 1$ diterima yang artinya pembayaran gaji yang tepat waktu serta jumlah besaran gaji yang sesuai sangat berpengaruh secara signifikan terhadap produktivitas kerja karyawan. Nilai koefisien sebesar 0,002 menunjukkan bahwa variabel gaji sangat berpengaruh terhadap produktivitas kerja karyawan. Pembayaran gaji yang tepat waktu memotivasi karyawan untuk tetap bekerja sesuai dengan target yang telah ditetapkan perusahaan, kepuasan terhadap gaji akan tercipta jika besarnya gaji disesuaikan dengan pengalaman kerja, tanggung jawab serta jabatan karyawan tersebut. Penyesuaian gaji dilakukan dengan menggunakan kriteria berdasarkan sistim kompetensi yang dimiliki oleh PT Freeport Indonesia. Gaji merupakan faktoryang sangatpenting,karenatidak dapat dipungkiri bahwa manusia bekerja untuk mendapatkan imbalan agar dapat memenuhi kebutuhan hidupnya. Hal ini sejalan dengan penelitian dari Nugroho et al. (2020) gaji berpengaruh terhadap produktivitas kerja Karyawan, dimana semakin besar gaji yang diterima maka akan meningkatkan produktivitas kerja. Gaji memberikan kontribusi terbesar terhadap naik turunnya produktivitas kerja karyawan (Lazuardi, 2020). Sistem pemberian upah atau gaji dapat memberikan pengaruh yang besar terhadap produktivitas tenaga kerja (Mukti et al. 2020).

\section{H3: Lingkungan kerja berpengaruh terhadap produktivitas kerja karyawan.}

Berdasarkan Tabel 6 menunjukan bahwa variabel lingkungan kerja memiliki hubungan positif dan pengaruh yang signifikan terhadap produktivitas kerja karyawan. Hal ini dibuktikan dengan nilai thitung yang lebih besar dari nilai t tabel, pada taraf nyata 5\% (1,948 $>1,668)$, dengan nilai koefisien sebesar 0,052 . Oleh karena itu, H3 diterima yang artinya lingkungan kerja berpengaruh secara positif dan signifikan terhadap produktivitas kerja karyawan. Hal ini menunjukkan bahwa hubungan karyawan dengan atasan maupun hubungan antar karyawan merupakan faktor utama dalam membentuk lingkungan kerja karyawan. Lingkungan kerja yang diteliti terdiri dari lingkungan kerja fisik dan lingkungan kerja non fisik. Berdasarkan hasil kuisioner, lingkungan kerja fisik sangat baik tetapi untuk lingkungan kerja non fisik yaitu hubungan antara atasan bawahan serta hubungan antar sesama karyawan perlu diperbaiki dan ditingkatkan dengan cara memperbaiki sistim komunikasi dilapangan, karena dengan komunikasi yang baik akan tercipta hubungan kerja yang baik serta lingkungan kerja harmonis antara atasan dan bawahan sehingga dapat meningkatkan produktivitas kerja karyawan Development di tambang bawah tanah DMLZ (Deep Mill Level Zone) PT Freeport Indonesia. Hal ini sejalan dengan penelitian Kisworo (2012) lingkungan kerja yang kondisif tercipta jika adanya interaksi antar karyawan, adanya komunikasi yang baik didalam perusahaan, tidak ada rasa saling curiga, dan memberikan kontribusi menjadi orientasi pada setiap. Kondisi lingkungan kerja nyaman, kondusif, dan menyenangkan akan mempengaruhi suasana kerja karyawan dan tentunya berpengaruh pada produktivitas karyawan karyawan (Astuti, 2020). 
Lingkungan kerja yang baik dan menyenangkan dapat meningkatkan semangat dan gairah kerja karyawan serta dapat menciptakan emosi yang baik dalam menyelesaikan tugas dan tanggung jawabnya (Junianti et al. 2020). Lingkungan kerja karyawan yang baik, peralatan penujang proses produksi, hubungan antar karyawan serta peran pemimpin akan membentuk budaya organisasi yang berpengaruh pada sikap dan perilaku karyawan dalam cara mereka bekerja sehingga dapat meningkatkan juga produktivitas kerja karyawan (Saputra et al. 2020).

\section{H6: Pengalaman kerja berpengaruh terhadap produktivitas kerja karyawan}

Berdasarkan Tabel 6 diketahui bahwa variabel pengalaman kerja memiliki hubungan positif dan berpengaruh secara signifikan terhadap produktivitas kerja karyawan, dibuktikan dengan nilai $t$ hitung yang lebih besar dari nilai $\mathrm{t}$ tabel, pada taraf nyata $5 \%$ $(1,948>1,668)$ dengan nilai koefisien sebesar 0,052 . Pengalaman kerja menunjukkan penguasaan seseorang terhadap bidang pekerjaan yang selama ini ditekuninya. Umumnya pengalaman kerja dapat diukur dengan melihat lamanya waktu yang dihabiskan tenaga kerja pada suatu bidang pekerjaan tertentu. Berdasarkan data responden atau karyawan development memiliki masa kerja dengan rentang 6-20 tahun adalah sebanyak $80 \%$, ini mengindikasikan bahwa secara pengalaman karyawan development telah berpengalaman didalam pekerjaan. Untuk menghindari kejenuhan dalam bekerja perlu dilakukan rotasi kerja individu antar section yang bertujuan untuk meningkatkan keterampilan, pengetahuan serta kompetensi yang dimilikianya. Rotasi kerja adalah proses memindahkan karyawan pada posisi baru dari satu tugas ke tugas lain untuk mengurangi kemonotonan dalam suatu rutinitas yang dilakukan karyawan, organisasi tersebut harus memiliki data dan jadwal yang terencana (Ariani et al. 2020). Selain rotasi kerja perlu dilakukan juga pengembangan organisasi dan sistim promosi jabatan. Promosi jabatan adalah perpindahan dari suatu jabatan ke jabatan lain yang lebih tinggi sebagai imbalan karena pretasi kerjanya yang baik, masa kerja yang lebih lama maupun faktor lainnya (Rismayanti et al. 2020). Pengalaman kerja berpengaruh terhadap produktivitas karyawan karena pengalaman kerja dapat menunjang terciptanya produktivitas yang optimal (Nangoy et al. 2020).

\section{Implikasi Manajerial}

Implikasi manajerial yang dapat memberikan perubahan dalam meningkatkan produktivitas kerja karyawan Development di tambang bawah tanah DMLZ PT Freeport Indonesia adalah (1) mengoptimalkan struktur gaji karyawan, kepuasan terhadap gaji akan tercipta jika besarnya gaji disesuaikan dengan pengalaman kerja, tanggung jawab serta jabatan karyawan tersebut. Penyesuaian gaji dilakukan dengan menggunakan kriteria berdasarkan sistim kompetensi yang dimiliki oleh PT Freeport Indonesia. (2) Memperbaiki sistim komunikasi dilapangan, karena dengan komunikasi yang baik akan tercipta hubungan kerja yang baik serta lingkungan kerja yang harmonis antara atasan dan bawahan. Kondisi lingkungan kerja nyaman, kondusif, dan menyenangkan akan mempengaruhi suasana kerja karyawan dan tentunya berpengaruh pada produktivitas karyawan karyawan (Astuti, 2020). (3) Melakukan rotasi kerja individu antar section dilakukan untuk memberikan suasana baru, menghindari kejenuhan terhadap rutinitas harian, agar karyawan dapat menguasai dan mendalami pekerjaan lain di bidang yang berbeda pada suatu perusahaan. Melakukan pengembangan organisasi, dilakukan sesuai dengan kebutuhan, tujuan serta perubahan yang terjadi di organisasi, serta memberikan promosi jabatan kepada karyawan, karena promosi merupakan imbalan dari organisasi atau perusahaan atas pretasi kerjanya yang baik, lamanya masa kerja dan faktor lainnya, karena berdasarkan data responden terdapat $80 \%$ karyawan yang telah memiliki pengalaman diatas 6-20 tahun masa kerja, namun perlu mempertimbangkan "the right man on the right place ".

\section{KESIMPULAN DAN SARAN}

\section{Kesimpulan}

Faktor yang berpengaruh secara signifikan terhadap peningkatan produktivitas kerja karyawan development di tambang bawah tanah DMLZ PT Freeport Indonesia adalah gaji atau upah, lingkungan kerja dan pengalaman kerja. Implikasi manajerial untuk meningkatkan produktivitas kerja karyawan adalah mengoptimalkan struktur gaji karyawan, dimana besarnya gaji disesuaikan dengan pengalaman kerja, tanggung jawab serta jabatan karyawan tersebut. Memperbaiki sistim komunikasi dilapangan, karena dengan komunikasi yang baik akan tercipta hubungan kerja yang baik serta 
lingkungan kerja harmonis antara atasan dan bawahan. Melakukan rotasi kerja individu antar section, hal ini dilakukan untuk memberikan suasana baru, menghindari kejenuhan terhadap rutinitas harian, agar karyawan dapat menguasai dan mendalami pekerjaan lain di bidang yang berbeda pada suatu perusahaan. Serta pengembangan organisasi dan sistim promosi, namun perlu mempertimbangkan "the right man on the right place and in the right time".

\section{Saran}

Saran untuk penelitian selanjutnya adalah perlu ditambahkan indikator lainnya seperti pengaruh teknologi, sarana produksi, jaminan sosial, manajemen, gizi dan kesehatan karyawan terhadap peningkatan produktivitas kerja karyawan. Pada penelitian ini menggunakan model yang searah dimana ketujuh variabel manifest seperti pendidikan dan pelatihan, skill atau keterampilan, motivasi, kedisiplinan, upah atau gaji dan lingkungan kerja menuju kepada satu variabel laten yaitu produktivitas kerja. Perlu dilakukan penambahan variabel mediasi sebagai perantara antara variabel manifest dan variabel laten. Saran untuk memperbaiki serta menjaga keharmonisan antar karyawan adalah mengadakan kegiatan outbond atau kegiatan keagamaan secara berkala, baik antara atasan dan bawahan, sesama rekan kerja maupun sesama keluarga karyawan Development di Tambang bawah tanah DMLZ (Deep Mill Level Zone), PT Freeport Indonesia.

\section{DAFTAR PUSTAKA}

Ariani D, Ratnasari S, Tanjung R. 2020. Pengaruh rotasi jabatan, disiplin kerja, dan beban kerja terhadap produktivitas kerja karyawan. Jurnal Dimensi 9(3): 480-493.

Asbari M, Purwanto A, Santoso B. 2020. Pengaruh iklim organisasi dan kepemimpinan transformasional terhadap produktivitas kerja inovatif pada industri manufaktor di Pati Jawa Tengah. Jurnal Produktivitas 7(1):62-69

Astuti RW. 2020. Pengaruh pendidikan, keterampilan kerja dan lingkungan kerja terhadap produktivitas kerja karyawan. Jurnal Sains Manajemen Dan Bisnis Indonesia 10(1):24-29.

Ghozali I, Fuad. 2014. Structural Equation Modeling: Teori, Konsep dan Aplikasi dengan Program LISREL 9.10 Edisi 4. Semarang: Badan Penerbit
Universitas Diponegoro.

Hasibuan M. 2012. Manajemen Sumber Daya Manusia. Edisi Revisi. Jakarta: Penerbit Bumi Askara.

Irawan A, Maarif S, Affandi M. 2015. Faktor-faktor yang mempengaruhi kinerja pegawai negri sipil di direktorat jendral pendidikan tinggi. Jurnal Administrasi Bisnis dan Manjemen (JABM). [diunduh 2020 Nov 21]: 1(1):56. https://doi. org/10.17358/jabm.1.1.56.

Jogiyanto HM. 2011. Konsep dan aplikasi structural equation modeling berbasis varian dalam penelitian Bisnis. Yogyakarta: UPP STIM YKPN

Junianti E, Rahayu N, Suriyanti. 2020. Pengaruh lingkungan kerja dan motivasi terhadap produktivitas pegawai. Jurnal Investasi 6(2):110-118.

Kisworo B. 2012. Hubungan antara motivasi, disiplin, dan lingkungan kerja dengan kinerja pendidik dan tenaga kependidikan sanggar kegiatan belajar eks karasidenan Semarang Jawa Tengah [tesis]. Yogyakarta: Universitas Negeri Yogyakarta.

Komaruddin. 2013. Manajemen Tenaga Kerja Indonesia. Edisi Kedua, Jakarta: Bumi Aksara.

Latifah S. 2020. Pengaruh karasteristik individu, keterampilan dan pemeliharaan kerja terhadap produktivitas kerja karyawan. Jurnal Syntax Idea 2(5):142-151.

Lazuardi S. 2020. Pengaruh gaji, insentif dan Lingkungan kerja terhadap produktivitas kerja karyawan divisi Merchandising PT Indomarco Prismatama Gresik. Jurnal Penelitian Ilmu Manajemen (JPIM) 5(3): 2502-3780.

Liana W. 2020. Pengaruh motivasi terhadap produktivitas karyawan PT Telkom Indonesia, Tbk Cabang Palembang. Jurnal Nasional Manajemen Pemasaran \& SDM 1(1): 65-72.

Ma'arif M, Kartika. 2012. Manajemen Kinerja Sumber Daya Manusia. Bandung: PT. Penerbit IPB Press.

Manulang M. 2005. Dasar-Dasar Manajemen. Yogyakarta: Gajah Mada Univ. Press.

Marayasa IN, Faradila A. Pengaruh motivasi dan disiplin kerja terhadap produktivitas karyawan PT Bank Dinar Indonesia. Jurnal Ekonomi Efektif 2(1): 110-122.

Mukti MH, Asmaroni D. 2020. Faktor-faktor yang mempengaruhi produktivitas tenaga kerja berdasarkan sistem pemberian upah borongan di Kabupaten Sampang (Studi Kasus Pembangunan ICU RSUD Kabupaten Sampang). Jurnal 
Manajemen Aset Infrastruktur \& Fasilitas. 4(1): 1-10.

Nangoy NM, Lengkong VPK, Uhing Y. 2020. Pengaruh motivasi kerja, pengalaman kerja dan stres kerja terhadap produktivitas pegawai pada Badan Perencanaan Pembangunan Daerah Kota Manado. Jurnal Riset Ekonomi, Manajemen, Bisnis dan Akuntansi (EMBA) 8(1):282-291.

Nugroho M, Normansyah. 2020. Pengaruh gaji, lingkungan kerja dan pengalaman kerja terhadap produktivitas kerja pegawai pada Kantor Dinas Perhubungan Kabupaten Asahan. Jurnal Manajemen, Ekonomi Sains 1(2): 2685-8754.

Prasetyo IF. 2016. Pengaruh rekrutmen dan pelatihan terhadap produktivitas kerja karyawan PT Starts Internasional Surabaya [tesis]. Bogor: Sekolah Pascasarjana, Institut Pertanian Bogor.

Rachmawati ANN. 2020. Strategi Pengembangan human capital dalam meningkatkan Kinerja Perusahaan [tesis]. Bogor: Sekolah Pascasarjana, Institut Pertanian Bogor.

Ravino J. 1985. Produktivitas dan manusia Indonesia.
Jakarta: Lembaga Sarana Informasi Usaha dan Produktivitas.

Rismayanti F, Mulia F, Komariah K. 2020. Peran promosi jabatan terhadap peningkatan produktivitas kerja karyawan. Jurnal Ekonomi dan Bisnis Universitas Udayana 9(3):303-312.

Saputra EF, Finthariasari M, Bustami T. 2020. Pengaruh lingkungan kerja dan budaya organisasi terhadap produktivitas kerjakaryawan. Jurnal Etrepreneur dan Manajemen Sains (JEMS) 1(2): 99-105.

Sarwono J, Narimawati U. 2015. Membuat skripsi, tesis, dan disertasi dengan partial least square SEM (PLS-SEM). Th Arie Prabawati, editor. Yogyakarta: Andi

Sedarmayanti. 2009. Sumber Daya Manusia dan Produktivitas Kerja. Bandung: Mandar Maju.

Simanjuntak PJ. 1998. Pengantar Ekonomi Sumber Daya Manusia. Jakarta: LP-FE, UI.

Wirawan P, Haris I, Suwena K. 2018. Pengaruh disiplin kerja karyawan bagian produksi pada PT Tirta Mumbul Jaya Abadi Tahun 2016. Jurnal Pendidikan Ekonomi Undiksha 10(1):305-315. 